


\section{Cuando decir Napoleón III significaba decir Hitler. Los biopics de Dieterle y Muni (1935-1939)}

\section{When Saying Napoleon III Meant Hitler: The biopics of Dieterle and Muni (1935-1939)}

Mauricio Sánchez Menchero Universidad Nacional Autónoma de México

Resumen

La productora de cine Warner Brothers se encargó de la creación de tres biopics sobre la vida de Louis Pasteur, Benito Juárez y Emile Zola. Esta trilogía producida durante los años previos de la II Guerra Mundial, periodo en el que se estableció de forma más contundente la censura en la industria, se convirtió en un material de propaganda antinazi a pesar de la presión del gobierno alemán en Estados Unidos y gracias a la astucia de dos artistas de origen judío en Hollywood: el actor Paul Muni y el director William Dieterle. Ambos usaron de forma creativa las figuras retóricas de la alusión o el símil, junto al del desplazamiento.

Palabras clave: cine, propaganda, biopic, judío, nazi.

Abstract

Film producer Warner Brothers created three biopics on Louis Pasteur, Benito Juárez and Emile Zola. This trilogy, made in the years before World War II, when censorship in industry was more 
forcefully established, became an item of anti-Nazi propaganda despite pressure from the German government. All this thanks to the ingenuity of two artists of Jewish origin in Hollywood: actor Paul Muni and director William Dieterle. Both used, in a creative way, the rhetorical figures of the allusion or the simile, next to the one of the displacement.

Keywords: Cinema, Propaganda, Biopic, Jewish, Nazi.

Para Eugenia Meyer

\section{Las posibilidades retóricas del biopic}

$7 \mathrm{n}$ los Estados Unidos los migrantes de diferentes posturas poClíticas se unieron contra el fascismo a partir de la llegada al poder de Adolf Hitler en 1933. Ya desde los años previos y durante la conflagración mundial, Hollywood se convirtió en un contrafuerte donde liberales, radicales y comunistas se organizaron para recaudar fondos en contra del Tercer Reich. De hecho llevaron a cabo campañas propagandísticas a través de la prensa, la radio y las producciones cinematográficas (Humphries, 2008: 35).

Para el presente trabajo nos interesa rescatar sólo una de estas relaciones establecidas a partir de diferentes posturas políticas y étnicas. Nos referimos a la mancuerna judía que conformaron el actor ucraniano Paul Muni (1895-1967) y el realizador alemán William Dieterle (1893-1972), quien tenía además, una orientación política de izquierda. Ambos artistas contaron con la protección y apoyo de Jack L. Warner (1892-1978), dueño de la productora Warner Brothers.1 De esta forma se combinaron sus habilidades y

1 Paul Muni nació el 22 de septiembre de 1895 como Frederich Meshilem Meier Weisenfreund en la ciudad de Lwów Austria-Polonia que luego fue cedida a la región de Galicia, Ucrania, en tiempos de la Unión Soviética. Apartir de la 
disciplinas artísticas y profesionales para realizar media docena de películas en el transcurso de cinco años, aunque aquí nos interesa solamente analizar la tríada de biopics o cintas biográficas que relataron trayectorias de personalidades científicas (Pasteur, 1935), artísticas (Zola, 1937) o políticas (Juarez, 1939).2 Sin duda se trató de un género fílmico que, en Hollywood durante los treinta, contó con producciones importantes. 3

caída del régimen comunista y con la independencia de Ucrania, dicha ciudad recibe actualmente el nombre de Lviv. En 1902 Paul Muni viajó con sus padres y hermanos hacia los Estados Unidos. En Nueva York, Muni participó como un joven actor en el Yddish Art Theatre, hasta que en 1926 actuó en la que fue su primera obra en lengua inglesa Weamericans. Su primera película fue The Valiant (1929) para los estudios Fox. A partir de ese momento dividirá su trabajo entre Broadway y Hollywood. / Nacido el 15 de julio de 1893, en Ludwigshafen am Reihn, Wilhelm Dieterle fue el más pequeño de nueve hermanos que vivían de forma indigente. Muy joven se unió a un grupo de teatro. En dicho ambiente fue descubierto por Max Reinhardt, el prolífico dramaturgo, guionista y actor alemán. En referencia a Reinhardt, Lotte H. Eisner (1998: 13) nos recuerda que éste ha sido clasificado erróneamente como un artista expresionista: él, como productor ya consagrado, sólo observó y apoyó un estilo que estaban creando las jóvenes generaciones de las que formó parte Dieterle. Agradezco esta referencia a mi colega el maestro Carlos Flores Villela. Dieterle participó como actor protagónico en más de 20 películas silentes, entre las que destaca Faust (1926) de F. W. Murnau. La primera experiencia de Dieterle como realizador fue Der Mensch am Wege (1923), basada en una obra de Lev Tolstói, en la cual compartía actuación con una muy joven Marlene Dietrich. En 1930 escribió, dirigió y actuó en su primer biopic basado en la vida del rey Ludwig II. Sin embargo, luego de dirigir una decena de películas, Dieterle realizaría en 1931 su último filme en Alemania debido a la llegada de los nazis. Dieterle cambió entonces su nombre por el de William y dirigió su primer filme en los Estados Unidos, The Last Flight (1931), para los estudios Warner Brothers.

2 Para Elefteriou-Perrin estas biografías cinematográficas son una muestra de la cultura rooseveltiana, es decir individuos convertidos en héroes del ideal democrático (2004: 67).

$3 \mathrm{Al}$ respecto, conviene tener presentes algunos ejemplos de biografías fílmicas de aquella época. Alrededor de Abraham Lincoln están las versiones de Da- 
De hecho, Thomas Elsaesser (1986) ha sugerido que un Estudio como Warner Brothers se interesó en el género biopic como respuesta al conservadurismo manifiesto en el Código Hays como se explicará más adelante-. Así, mediante el desplazamiento de la exactitud histórica por un realismo social contemporáneo, la película biográfica podía sugerir que el llamado a la censura no fuera elaborado tanto por la internalización crítica y la autocensura, "sino por una especie de desplazamiento textual de los valores exhibidos (realismo por autenticidad; sexo por cultura europea y sofisticación; cuestiones domésticas y sociales por política mundial)" (Robé, 2009: 79).

Ciertamente las metáforas en el cine pueden construirse a partir de la confrontación de hechos - como indica Jean Mitry- "o actos según las contigüidades que resultan normalmente del montaje”.4 Nosotros ańadimos que también pueden aparecer como resultado de la construcción de símiles históricos "cuyas connotaciones están siempre por descifrar. La metáfora no es dada; sólo existe como tal (su sentido) en la mente del espectador" (Mitry, 1990: 124-125).

En este sentido, la alusión es una perífrasis que sirve para referirnos a las personas sin nombrarlas o hacerlo a través de otros. Se trata de una comparación entre un término real y una imagen. La principal utilidad de esta figura retórica es que permite insinuar

vid W. Griffith (1930), de John Ford (1939) o de John Cromwell (1940). En cuanto a la biografía de monarcas femeninas puede mencionarse la de la reina María Cristina (Queen Christina, 1933) con Greta Garbo dirigida por Rouben Mamoulian; Cleopatra (1934) de Cecil B. DeMille con Claudette Colbert, y Catalina la Grande (The Scarlet Empress, 1934) de Josef von Stemberg con Marlene Dietrich.

${ }^{4}$ Desde el giro pictográfico, los estudios de la imagen, como se pretende en el presente texto, demandan actualmente del investigador "un complejo juego entre la visualidad, los aparatos, las instituciones, los discursos, los cuerpos y la figuralidad". Lo que incluye el descubrimiento de la actividad del espectador (Mitchell, 2009: 23). 
de forma indirecta a los sujetos: uno recuerda a otro provocando una idea sugerida en la apreciación del público. Este tipo de discurso comparativo y persuasivo ha sido utilizado no solamente en la literatura, sino también en el séptimo arte. El ejemplo del biopic Danton (1983) nos puede ayudar a tener presente la función de la alusión.5

En este largometraje, Andrzej Wajda presentaba algunos de los personajes envueltos en el movimiento histórico de la Revolución francesa. Pronto comenzaron a circular comentarios que señalaban cómo la película de Wajda hacía un símil con la situación polaca de fines del siglo XX: se hacían alusiones a la situación que se vivía en Polonia a partir de la declaración de la ley marcial (1981). Wajda negó haber hecho cualquier alegoría. Sin embargo, no podía pasar desapercibido el parecido político del tirano Robespierre y del pensador Danton con los que provenían respectivamente de los líderes polacos, el general Wojciech Jaruzelski y el líder sindical Lech Walesa (Falkoswska, 2007: 199-200). De igual forma, Wajda aludió, en la secuencia del juicio a Danton, no sólo los famosos

5 Otro caso proviene del bioepic Iván el Terrible (parte I, 1945) de Sergei Eisenstein. La escena que particularmente importa destacar es la que muestra al pueblo que viene en procesión desde Moscú a encomiar a su zar en la ciudad de Aleksándrov para pedirle que vuelva a la capital. Pero aquí aparece la intervención directa de Joseph Stalin en la película. El líder soviético deseaba utilizarla como una alegoría de su propio ascenso al poder justo cuando enfrentaba a los nazis. En dicha escena apoteósica, en la que el pueblo ruso marchaba hacia la torre en la que Iván permanecía escondido era, según los propósitos de Stalin, una alusión de su propio mandato: supuestamente un personaje popular para tomar el poder después de la marcada ausencia del gran líder revolucionario Vladimir Illyich Lenin. Sin embargo, un análisis atento de la película permite observar que la representación del regreso al poder por parte de Iván no sirvió para transmitirlo como el símil que Stalin quería. Por el contrario, en la cinta de Eisenstein el zar representado de forma grandilocuente, se acercaba más a un personaje siniestro y distanciado de su gente que a un buen monarca (Conroy, 2012: 3-4). 
"procesos de Moscú", sino también el tipo de juicio al que se enfrentaron los miembros de Solidaridad. La clave para revelar esta alusión proviene de la obra de teatro "L'Affaire Danton" ("El caso Danton") en la que se basa la película y cuya puesta en escena se había llevado a cabo en Gdansk en 1980. Su director, Maciej Karpinski, había declarado que dicha obra se había estrenado después de la represión al movimiento sindical Solidaridad como una especie de denuncia.6 De esta forma, la figura retórica de la alusión ha sido utilizada en el cine para evocar, a través de un hecho del pasado o una situación determinada, otro evento histórico u otro entorno semejante. La segunda figura que utilizaré en este texto es la de desplazamiento que ejemplifico con la película de The Life of Emile Zola (1937).

Ahora bien, en cuanto a la producción hollywoodense, según señala Thomas Doherty (2007 y 2013), el régimen nazi no sufrió crítica alguna desde la llegada de Hitler en 1933 y hasta 1939 cuando se estrenó la película Confessions of Nazi Spy realizada por Warner Brothers.7 Pero hasta entonces los grandes estudios esta-

6 Karpinski dijo también que los propios públicos polacos veían en la película Danton "una metáfora clara de su situación actual". Por su parte, el actor Gerard Depardieu se declaró a favor del sindicato Solidaridad durante el rodaje; lo mismo hizo Andrezj Seweryn, que actuaba como el traidor Léonard Bourdon, y que formó un Comité de Coordinación de la Solidaridad en Francia cuando se declaró la Ley marcial (Mazierska y Goddard, 2014: 46).

7 HervéDumont indica que la acogida de la película Juarez resulta interesante, "pues su estreno neoyorquino precede de 48 horas al de otra producción Warner, The Confessions of a Nazi Spy, la primera película abiertamente antinazi de Hollywood. Este pequeño film policiaco... denuncia las maniobras de una red de espionaje alemán en Manhattan; los malvados nazis reemplazan a los gángsters habituales. Pero el estreno casi simultáneo de las dos películas no es fortuito: a la apología de época de las ideas democráticas sigue la necesidad de defenderla ahora y de manera concreta en suelo americano. Además, las dos películas alcanzan también a un público internacional, pues desde el 30 de abril los visitantes de la Exposición Universal han invadido Nueva York" (Dumont, 1994: 121). 
dounidenses habían corrido un velo ante los acontecimientos políticos que se vivían en Alemania.

Para explicar esta compleja relación de cooperación y desaprobación entre el gobierno nazi y los grandes estudios de los Estados Unidos es necesario tener presente una serie de variables, como la situación geopolítica -después de la Primera Guerra Mundial y la crisis financiera de 1929, la nación norteamericana no quería entrar a nuevo conflicto europeo- o el peso de la conciencia moral ante las noticias que hablaban de persecución étnica. Pero fue, sobre todo, el aspecto comercial y económico lo que tuvo un mayor peso: en juego estaba el mercado alemán de películas estadounidenses, el mayor de Europa (Doherty, 2013: 10).

El primer antecedente de cooperación y rechazo entre gobierno nazi y estudios norteamericanos provino de Joseph Goebbels cuando éste aún no era un funcionario de Estado. El que iba a convertirse en jefe de propaganda de Hitler había encabezado a un escuadrón de camisas pardas durante una manifestación en contra de la cinta pacifista All Quiet on the Western Front (Sin novedad en el frente, 1930) con bombas pestilentes y gritos de "película judía" en un cine berlinés. En medio de una gran depresión económica y con más de cinco millones de desempleados, la república de Weimar terminó por cancelar la licencia de exhibición de esta película y afectar económicamente a la Universal Pictures. Este hecho no sería sino uno de los primeros antecedentes antisemitas relacionados con el mundo del cine. Ya para la llegada de los nazis al poder, se aprobaría una ley que prohibía que los judíos pudieran participar en películas alemanas; este hecho impulsaría a que muchas de las principales personalidades dedicadas al cine, de origen semita, emigraran a los Estados Unidos.

Aquí conviene recordar a uno de los migrantes alemanes de ascendencia judía, el teórico Siegfried Kracauer, quien analizaría las "tendencias íntimas del pueblo germano", gracias al estudio his- 
tórico del cine alemán que le ayudó a comprender y explicar el poderío y la ascensión de Hitler (Kracauer, 1985: 19). Así, por ejemplo, Kracauer contextualizó la expansión del cine expresionista en Alemania. Hoy resulta claro que el káiser siempre apreció el cine tanto por su magia para contar historias como por su capacidad de convocatoria hacia a la identidad nacionalista. 8 Este fue el caso de los filmes prehitlerianos que retrataban la era napoleónica para dar lugar al enfrentamiento Prusia versus Napoleón Bonaparte (Kracauer, 1985: 244). Sin duda la industria cinematográfica debía estar al servicio del Tercer Reich. No es de extrańar, entonces, que la productora alemana Universum Film AG (Sadoul, 1972: 144) se convirtiera en un monopolio propagandístico. En sentido contrario, la censura al cine no alemán se volvió una tarea básica del nacionalsocialismo.

Goebbels estaba empeñado en utilizar el cine como elemento de propaganda, tanto en sentido positivo como en el negativo. En este último sentido, presumirá, tras la conquista nazi de París, de haber dado órdenes estrictas para que no se produjeran en la Francia ocupada más que películas tontas (Paz y Montero, 2002: 71).

Así, pues, ante la amenaza del gobierno nazi de prohibir la exhibición de filmes americanos, tres de los grandes estudios -Fox, Paramount y Metro-Goldwyn-Mayer- que habían invertido en las oficinas de distribución alemanas con buenos resultados económicos, decidieron permanecer bajo el régimen nazi. Además, no sólo mantuvieron la distribución de películas, sino que decidieron

8 Es conocido el gusto de Hitler por el cine. Ya desde joven gozó de una película como Der Tunnel, basada en una novela de Bernhard Kellermann y dirigida, en su primera versión, por William Wauer (1915) (Zalampas, 1990: 26). Otra de sus cintas predilectas fue Der Rebell, de Luis Trenker, en donde se relataba un episodio de guerra: la resistencia del Tirol al ejército napoleónico (Kracauer, 1985: 242-243). 
retirara personal judío de algunos puestos claves en sus despachos en Alemania.9 En cambio Warner Brothers cortó relaciones por completo. Una razón de peso para los hermanos Warner provendría del ataque personal sufrido por el judío británico Phil Kaufman, a manos de camisas pardas lo cual, aparentemente, le causaría finalmente su muerte en Berlín a principios de 1933. Esto fue suficiente para que Harry y Jack Warner decidieran abandonar la relación con la Alemania nazi a fines de 1933, dirigiendo su estudio bajo una postura claramente antinazi. Durante un brindis en el preestreno de la película Confessions of Nazi Spy, Groucho Marx diría que Warner era el único estudio con agallas. Otra postura sería la que tomaron otras compañías productoras como RKO, UnitedArtists, Universal y Columbia. Éstas no cerrarían sus oficinas en Alemania, sino que únicamente trasladarían su personal fuera de Berlín.

En los Estados Unidos, mientras tanto, la censura cinematográfica siguió acechando únicamente temas de violencia y sexo en las pantallas tal y como, desde 1930, efectuaba la Motion Picture Production Code, mejor conocido como Código Hays. Como se sabe, este reglamento era un conjunto de directrices para mantener bajo control la "moral laxa" que se vivía en la cultura cinematográfica. Además, desde 1934, se le había otorgado más poder de

9 Al llegar los nazis al poder publicaron decretos antisemitas. Es el caso de la purga generada por los Gesetzzur Wiederherstellung des Berufsbeamtentums -Ley llamada de la Restauración del Servicio Civil- publicada el 7 de abril de 1933. En uno de sus párrafos se justificaba que para "simplificar la administración", los funcionarios que no habían sido sometidos a "la formación habitual" o no eran "apropiados" habrían de perder sus puestos de trabajo. "La ley incluía una cláusula 'aria', con el resultado de que sólo en Prusia hubieron de abandonar el cuerpo judicial 128 jueces y fiscales judíos. Como siguieron luego miembros de profesiones liberales y profesionales de otras actividades ajenas al sector estatal, a menudo por voluntad propia, esto equivalió a una licencia general para decidir quién podía trabajar y quién no" (Burleigh, 2007: 279). 
acción al Código gracias a la creación de una oficina bajo la dirección de Joseph I. Breen: un católico de ascendencia irlandesa que expresaba su preocupación por garantizar la equidad en el trato con otros países.10 Esta postura se convertiría en su famoso "a see-no-evil, hear-no-evil policy towards any regime on the planet" (Doherty, 2013: 43). Y para no molestar al Dr. Georg Gyssling, cónsul nazi en Los Ángeles, que definía al cine como un mero espectáculo fueron censurados dos proyectos fílmicos antinazis en los Estados Unidos: una película cuyo título era "The Mad Dog of Europe"(1933)11 y un documental, "Hitler's Reign of Terror"

10 Joseph I. Breen no ocultaba su admiración por Hitler y Mussolini y, en cambio, daba muestras de mantener una postura más bien antisemita.

11 El guionista judío Herman J. Mankiewicz, que luego escribiría Ciudadano Kane, quiso denunciar el ultraje que estaba padeciendo la población de origen judío en Alemania. Para ello escribió la obra "The Mad Dog of Europe", que envió a su amigo y paisano Sam Jaffe, productor de RKO. Jaffe adquirió los derechos y se dio a la tarea de planear un elenco de Hollywood para logar una cinta que sirviera para concientizar a la opinión pública. El cónsul alemán Georg Gyssling, no pudo utilizar el artículo 15 contra la producción de esta película porque se trataba de una empresa independiente que no tenía relación con Alemania. Ante esta situación, Gyssling acudió a la Oficina Hays para hacer una amenaza: si en Hollywood se realizaba la película, entonces los nazis prohibirían la proyección de películas estadounidenses en Alemania. La primera reacción de WillHays, como presidente de la organización, fue la de llamar a Jaffe y Mankiewicz para advertirles de las consecuencias económicas que provocaría el filme. Sin embargo, ambos insistieron en que iban a llevar adelante su plan. Hays entonces presionó a través del consejo asesor de la Liga Anti-Difamación en Los Ángeles y de las grandes productoras interesadas en conservar su negocio en Alemania. Al final la película no se llevaría a cabo a pesar de un último esfuerzo llevado a cabo por Al Rosen (Urwand, 2013: 72-74). Este último, que era un representante de Hollywood y portavoz de la March of Time Productions, al ser entrevistado por un enviado de la Jewish Telegraphic Agency, dijo que se resentía por la interferencia de los funcionarios del Reich. "Sé de buena fuente, dijo Ross, que la organización Hays fue abordado por representantes del Dr. Luther y del Dr. Gyssling de Los Ángeles para utilizar su influencia sobre los productores de Hollywood y hacerme detener la producción de The Mad Dog of 
(1934).12 Por su parte, en la Alemania nazi, se llevaría a cabo la censura de varios largometrajes estadounidenses lo que, a fin de cuentas, causaría pérdidas a los estudios cinematográficos.

Sin embargo, ya para 1940, películas como Foreign Correspondences de Alfred Hitchcock y The Great Dictator de Charles Chaplin, formarían parte del reducido número de filmes de Hollywood, claramente antinazis, que ayudarían a influir "en la preparación del pueblo americano para la intervención en el conflicto mundial. El propio [Franklin] Roosevelt no dejó de agradecer este apoyo a su política, que -lógicamente- desagradaba a los partidarios del aislacionismo" (Paz y Montero, 2002: 286-287).

\section{Louis Pasteur}

La imagen de Napoleón III, con sus largos bigotes encerados, fue representada por un par de actores en las películas de Dieterle. Para el caso de Pasteur, el monarca francés fue interpretado por Walter

Europe" (ver: http://www.jta.org/1933/10/23/archive/charges-nazis-here-usingthreats-to-halt-production-of-mad-dog-of-europe).

12 El camarógrafo aficionado Cornelius Vanderbilt Jr. recogió las imágenes de la llegada de Hitler al poder, así como algunos mítines nazis celebrados en 1933. Convertido en todo un contrabandista, Vanderbilt lograría sacar de Alemania este valioso material fílmico. Un año más tarde, ya en Estados Unidos, las tomas serían convertidas en el documental Hitler's Reign of Terror de 55 minutos de duración bajo la dirección de Michael Mindlin y el guión de Edwin C. Hill quien también participó como narrador del mismo. Curiosamente el documental incluía escenas donde se recreaba una supuesta entrevista a un falso Hitler; hasta el momento no se sabe quién ni en dónde fue realizada. Tampoco se sabe cómo sucedió que la única copia existente del filme fuera a parar a las bodegas de la Cinémathèque Royale de Belgique (Bruselas), lugar en donde sería hallada en 2013. Posiblemente después de su estreno y pronta censura en los Estados Unidos, una copia debió llegar a Bélgica antes de la invasión nazi en mayo de 1940. Al parecer Ernest Hemingway colaboró en el documental (Urwand, 2013: 187). 
Kingsford.13 En cambio, para Juarez, el papel estuvo ejecutado por Claude Reins.14 En ambas actuaciones, el papel de "Napoléon le petit" fue utilizado por Dieterle como una clara alusión a Adolf Hitler, otro tirano con bigotes. 15

De la misma manera, en el inicio de la película de Juarez, Dieterle rememoraba cómo Luis Napoleón, en tan solo cuatro años, había pasado de la presidencia a una monarquía expansionista como lo patentizaba la intervención en México. Este mensaje fue un guiño a los públicos de la película, inicialmente el norteamericano, para advertir cómo Hitler estaba siendo una copia del monarca francés: en menos de un ańo de haber llegado al poder se había convertido en el führer que, primeramente, impulsaría la anexión de Austria y los Sudetes checoslovacos (1938), para continuar con la ocupación militar de Polonia en 1939, situación que desataría finalmente la Segunda Guerra Mundial.

13 Walter Kingsford también aparecería en la película de Juarez pero actuando ya no como Napoleón III, sino como el príncipe Richard von Metternich.

14 Es probable que la fisonomía afrancesada de Claude Reins le facilitó, como actor de Warner, su contrato para representar al capitán Louis Renault en la película Casablanca (1942).

15 En fotografías y documentales, la imagen de Hitler, ya como líder nazi, nos lo revela con su recortado bigote, pero no hay que olvidar que durante la Primera Guerra Mundial tenía unos bigotes alargados al estilo de Otto von Bismarck. También hay que recordar que los bigotes de Hitler se convirtieron en el elemento que mejor lo satirizaron en los Estados Unidos para la década de los cuarenta (Ross, 2006). Al respecto Charles Chaplin cuenta como Alexander Korda le había sugerido en 1937 que debía hacer una historia de Hitler basada en una falsa identidad: "ya que Hitler tenía el mismo bigote que Charlot... En mi papel de Hitler, podía yo arengar a las multitudes en una jerga de mi invención y hablar todo lo que quisiera. Y en mi otro papel de vagabundo, podía permanecer más o menos callado. Una parodia de Hitler era una ocasión para la burla y la pantomima. Con gran entusiasmo, volví apresuradamente a Hollywood y me puse a trabajar en el guión. El rodaje de la película [The Great Dictator) me llevó dos ańos...” (Chaplin, 1993: 434). 
Para Eric Hobsbawm resulta posible trazar un símil entre los fracasos y logros del emperador francés y del dirigente nazi:

[Napoleón III] fue un notorio fracasado en sus empresas políticas internacionales e incluso interiores... [Por su parte] Hitler pudo sobrevivir a la unánime reprobación de la opinión mundial, por cuanto es innegable que este hombre malo, psicópata y aterrador consiguió cosas extraordinarias en el camino hacia una catástrofe probablemente inevitable; no fue poco mantener el sólido apoyo de su pueblo hasta el final. Napoleón III no fue desde luego tan extraordinario ni tan loco (1998: 110).

Por su parte, el Napoleón III que aparece en la película Pasteur lo hace de forma fugaz con sólo un par de escenas. 16 Sin embargo, los guionistas de Warner, Sheridan Gibney y Pierre Collings, 17 aprovecharon la imagen de este monarca para presentarlo como un tirano -que en realidad no lo fue en su relación con Pasteur-y contrastarlo con la agudeza y honestidad científica del químico francés. Desde luego la película no perseguía una reconstrucción histórica exacta y pormenorizada, sino la recreación biográfica de Pasteur de forma entretenida y sin dejar de lado la propaganda contra la tiranía nazi. Pero esta libre recreación dejó de lado el hecho de que Louis Pasteur, para el momento en que está situada la película, la década de 1860, ya era director de la Escuela Normal

16 La aparición de Napoleón III apenas dura siete minutos hasta que vemos a un hombre descolgar su retrato y poner, en su lugar, al del presidente Louis Adolphe Thiers.

17 Sheridan Gibney y Pierre Collings recibieron el Oscar por mejor historia original y guión de la película Pasteur. Al parecer Edward Chodorov también participó en el script, aunque sin crédito. En 1953 el nombre de Chodorov va a aparecer en la lista negra, por parte de los estudios de Hollywood, debido a su falta de cooperación con el Comité de Actividades Antiamericana (House Committee On Un-American Activities), siendo además acusado de pertenecer al Partido Comunista en los Estados Unidos. 
Superior y también integrante de la Academia de Ciencias. Además, a solicitud de Napoleón III, Pasteur había emprendido

el estudio de las enfermedades del vino, [así] volviendo a los lugares de su infancia, se instaló en Arbois (Jura) para verificar personalmente las investigaciones y observar el desarrollo y la evolución del mosto. Allí descubrió que la alteración del vino proviene de gérmenes que proliferan a su antojo en instrumentos mal lavados. También inventó la pasteurización: basta con calentar el líquido unos cuantos minutos fuera del aire, entre 50 y $60^{\circ} \mathrm{C}$, para eliminar la contaminación sin alterar sus cualidades enológicas (Latour, 1995: 14-15).

En cambio, los guionistas Gibney y Collings nos cuentan, de una forma diferente y en escasos minutos, la solicitud que hiciera el emperador a Pasteur sobre el vino. Por ejemplo, en la primera aparición de Napoleón III en el filme de Pasteur lo vemos en las Tullerías acompañado por la emperatriz María Eugenia, al tiempo que lee un apócrifo panfleto impreso por Pasteur 18 -donde avisa sobre el peligro de la fiebre puerperal- lo que da pie al siguiente diálogo con el Dr. Charbonnet:

—Napoleón III: ¿Louis Pasteur?

-Charbonnet: No es un médico, sino un químico.

—N III: ¿Químico? No me diga.

-Ch: Recordará que hace algunos año sostuvo una polémica sobre la fermentación del vino.

—N III: Oh sí, lo recuerdo.

-Ch: Había unos animales. Seres infinitamente pequeños.

—N III: Pero tales criaturas, ¿existirán en realidad?

18 El panfleto impreso, parcialmente atribuido a Pasteur como aparece en la película, no es más que una burda síntesis del título de un artículo académico firmado por Pasteur, Joubert y Chamberland (1922). 
-Ch: Los organismos microscópicos son bien conocidos. Se crean espontáneamente cuando hay putrefacción. Son el resultado y no la causa de la enfermedad. Hirviendo el vino, el Sr. Pasteur los ha destruido. He deducido que pretende buscar sus pacientes haciendo hervir su sangre.

-N III: ¡Quiera Dios que no!

-Ch: No sería capaz.

-N III: Imposible Charbonnet. No lo toleraría. ¡No estamos en la Edad Media! Estamos en Francia, en el París del siglo XIX. Aparece en cuadro la emperatriz sirviendo unas tazas de té.

-María Eugenia: El Sr. Pasteur tiene derecho a defenderse.19

—Ch: Pero su majestad...

-ME: Igualmente he leído el panfleto, Dr. Charbonnet. No habla de hervir la sangre, sino los instrumentos de los cirujanos.

- Ch: Si me vieran hervir mis instrumentos, o lavarme las manos, me tomarían por un hechicero y debería salir del hospital.

En cuanto a la publicidad de la película llama la atención cómo se buscó presentar este biopic como un género nuevo que no por narrar la vida de un científico era menos atractiva en su trama. Un anuncio daba cuenta que la tensión del público era tal que podía escucharse hasta el sonido de un alfiler cayendo en el suelo (Foto 1). Este comentario que resulta exagerado, no lo fue en el momen-

19 El respaldo académico con el que contaba Pasteur pero también su carácter lo llevaron a enfrentar a Napoleón III sin miedo alguno y no como aparece en la película. Ejemplo de ello fue la carta que dirigió al emperador en 1867. Un documento en el que Pasteur le explicaba la trascendencia de sus estudios sobre la fermentación y los organismos microscópicos dentro de la química fisiológica. El propósito era pedir su apoyo económico para poder contar con un laboratorio más amplio, cómodo y sin peligro para la salud pública. Pero no hubo tal apoyo porque las arcas imperiales estaban vacías y los escasos fondos ya habían sido asignados para el nuevo teatro de la ópera de Charles Garnier. Lo anterior hizo que Pasteur se enfureciera y escribiera un artículo para el Moniteur con el fin de movilizar a la opinión pública contra tal decisión presupuestaria (Debré, 1998: 141-142). 
to de su estreno pues tuvo buena acogida gracias a un guión que presentaba de forma ágil lo que puede considerarse uno de los primeros biopics centrados en científicos 20 y en los microbios. 21 Hay que recordar que durante la exhibición de la película, los públicos pudieron contemplar no solamente la escena donde Pasteur miraba a través de un microscopio, sino que también miraron lo que supuestamente el científico observaba: una toma micrográfica de dichos seres vivos revueltos y aumentados al tamańo de la pantalla de proyección (Fotos 2 y 3). También los espectadores pudieron contemplar al matrimonio de Louis y Marie Pasteur, quienes acostados reposaban en su cuarto no en una misma cama, sino en dos individuales. Una escena que hablaba no tanto de la higiene que pedía Pasteur a los médicos, sino del Código Hays que impedía escenas de una pareja metida en el mismo lecho.

Finalmente la apuesta de Warner en Pasteur resultó un éxito en taquillas por el tema novedoso bien trabajado en el guión y los diálogos 22 pero también, sin duda, gracias a la actuación de Muni

20 El periodista Harold W. Cohen, por ejemplo, indicaba que los temas científicos resultaban por lo general aburridos, pero la película Pasteur rompía el esquema y la taquilla. ("Scientific history invariably is a thoroughly unattractive subject, filled with dry and static test-tube data, but The Story of Louise Pasteur dramatizes the life of this distinguished humanitarian with an enthusiasm that completely disrupts the established order of the box-office"). Pittsburgh Post-Gazette (14/03/1936), New York Public Library, Paul Muni Papers, Series III, Box 6 T-Mss 1967-005.

21 Conviene recordar que gracias a los rayos $\mathrm{X}$ distintos científicos empezaron a desarrollar el uso del cine dentro de la micrografía. Destacan, por ejemplo, el estadounidense L. G. Cole y, desde luego, JanComandon, el cual gracias al apoyo del productor cinematográfico Charles Pathé pudo montar un laboratorio de cine-micrografía y filmar numerosas películas de bacteriología, parasitología, hematología y numerosos temas (Medina, González y Velázquez, 1996: 492). 22 Eileen Creelman apuntaba cómo Warner había estructurado esta biografía a la manera de un libro más que centrarse en un incidente ("This time [Warner] have chucked out the usual movie plot, using the dramatized biographical 
apoyada en el trabajo de los maquillistas y por una espléndida dirección. A este respecto Muni apuntaba que "la única razón del maquillaje es que puede hacer cambiar más completamente en el carácter que se está interpretando. Pero se espera que el público no sea consciente del maquillaje sino de la interpretación del personaje en turno".23

\section{Benito Juárez}

Después del éxito comercial de Pasteur, Warner buscaría poner en manos de Dieterle y Muni un par de biopics más como lo iban a ser Zola y Juarez. Ambas producciones contarían con los servicios del productor de origen alemán Henry Blanke -aunque en Zola no aparece su crédito-. Para el libreto de Juarez, Blanke contrataría en un primer momento a Aeneas MacKenzie quien comenzaría a trabajar desde junio de 1938 bajo la inspiración de obras cuyos derechos había adquirido Warner tiempo atrás. Se trataba de Juarez and Maximilian (1925), del dramaturgo judío Franz Werfel,24 y de Phantom Crown: The Story of Maximilian and Carlota of Mexico (1934), de la novelista alemana afincada en México Bertita Harding.25 Y aunque MacKenzie contaría con los materiales histó-

method of books rather than centering the film about one incident"), The New York Sun (10/02/1936), New York Public Library, Paul Muni Papers, Series III, Box 6 T-Mss 1967-005.

23 Recorte de entrevista sin fecha ni título del periódico. New York Public Library, Paul Muni Papers, Series III, Box 6 T-Mss 1967-005. Al respecto Siegfried Kracauer señalaba que había muy pocos actores capaces de metamorfosearse: en primer lugar Paul Muni, luego LonChaney y Walter Huston (Kracauer, 1960: 101).

24 Una obra donde Werfel "logra hacer sentir, de principio a fin, la presencia del héroe mexicano sin que éste apareciera nunca en escena" (Pitol, 1995: 43). 25 Tanto la obra de Franz Werfel como la de Bertita Harding aparecen con créditos en la película de Juarez. 
ricos recabados por Jesse John Dossick y la traducción de Juárez el impasible del escritor Héctor Pérez Martínez (1933),26 en su libreto la imagen de Maximiliano se agigantaría frente a un Juárez muy reducido.

Para equilibrar el trabajo de MacKenzie, Blanke llamó entonces al dramaturgo Wolfang Reinhardt y a John Huston; a este último lo había conocido un año antes en la película Clitterhouse.27 De esta forma los tres libretistas trabajarían coordinadamente desde 1937. Según John Huston el trabajo del grupo colaborativo funcionó de manera armónica:28 "Wolfang poseía un conocimiento académico de Europa durante el periodo de Napoleón III y los

26 En el archivo de esta película se resguarda la traducción mecanografiada al inglés de Robert Callaway sobre el libro Juárez el impasible de Héctor Pérez Martínez. En sus notas, el traductor apuntaba que la obra, en su conjunto, no era favorable a Juárez. Además el "trabajo también es desigual. La escritura es a la vez florido y descuidado... El libro está repleto de citas (la mitad del libro está entre comillas)". Sin embargo, Callaway rescataba algunos incidentes y descripciones que podrían utilizarse en el libreto. En el mismo archivo se conserva el expediente de casi 200 páginas con notas, documentos históricos y bibliografía, elaborado por el investigador Jesse John Dossick -School of Education New York University-, y que lleva por título "Some notes on the life of Benito Juárez". Entre otros materiales se citan: extractos del diario de Juárez y cartas, así como la proclama "En el primer día del Año Nuevo 1865". También están trascripciones de discursos y biografía de Juárez escrita por Miramontes, extractos de "Benito Juárez" de Juan de Dios Peza y "Benito Juárez" de Rafael de Zayas Enríquez. Sobre el asesinato de Abraham Lincoln está la correspondencia entre Romeo y Seward y una circular de Lerdo de Tejada. Dieterle Box (2) Exp. 5: A, 5: 3 y 5: 4 Coll. 17 Juarez, University of Southern California.

27 Clitterhouse, producida por Warner y dirigida por el judío Anatole Litvak, contó en su papel protagónico con la actuación del actor también de origen judío Edward G. Robinson. Este intérprete actuaría en la obra dramática Juarez and Maximilian de Werfel.

28 Phantom Crown / esquema de continuidad por Wolfang Reinhardt / Compilado por A. E. MacKenzie. Dieterle Box (2) Exp. 5: C. Coll. 17Juarez, University of Southern California. 
Habsburgo; yo era un demócrata jeffersiano con ideas similares a las expuestas por Juárez y MacKenzie creía en el sistema monárquico... Así que la escritura fue dialéctica" (Grobel, 2000: 194). Conviene resaltar la recomendación de Reinhardt sobre la construcción de los diálogos:

que como son de política e ideología, deben constar de frases familiares de los periódicos de hoy en día; cada niño debe ser capaz de darse cuenta de que Napoleón, en su intervención mexicana, no es otro que Mussolini o Hitler en su aventura española.29

Luego de casi un año de trabajo el libreto estaba concluido. Huston, Reinhardt y MacKenzie se lo enviarían a Hall Wallis y Blanke. Ambos productores darían su aprobación. Pero el guion final todavía sufriría unos cambios. El problema se presentaría precisamente cuando Paul Muni, quien encarnaría a Juárez -tenía firmado un contrato con Warner que le permitía rechazar o no los guiones-30 manifestó que la imagen del presidente mexicano estaba opacada por la de Maximiliano y Carlota en número de escenas y diálogos como aquella en donde aparecían los monarcas escuchando a una mujer cantar "La Paloma".31 Ante esta situación, los Estudios hicieron caso a la estrella cinematográfica y se

29 El expediente de 141 páginas lleva por título "Phantom Crown by Wolfang Reinhardt" tiene escrita la fecha de 15 de febrero de 1938. Al interior del mismo conserva algunas hojas sueltas manuscritas y con anotaciones al margen. William Dieterle Box (2) Exp. 5: C Coll. 17 Juarez, University of Southern California. Las cursivas son mías.

30 Paul Muni, Papers Series III, Boxes: b 1 f 6 / b 1 f 7 T. MSS 1867.005, New York Public Library.

31 En opinión de Bette Davis el problema de la película Juarez es que se trataba de dos argumentos. Ella y Brian habían terminado en el set cuando apenas comenzaba Muni. Para Muni, desde luego, el papel de Juárez debía sermás importante que el de Carlota. Así que él y su mujer, Bella Muni, se encargaron de cortar muchas escenas de la película. (Chandler, 2006: 138). 
pidió a los guionistas se hicieran los ajustes necesarios. Mientras tanto Muni realizaría un viaje a México en compañía de Dieterle y Wallis (Foto 4).32

Al parecer Huston, bastante molesto con el ego de Muni, se hizo a un lado. Los ajustes y reestructuración del guion quedaron entonces en manos de Reinhardt y MacKenzie, quienes también contarían con el apoyo de Abem Finkel -especialista en diálogos pero sin crédito en la película-. En una conversación con Blanke, Muni le manifestaría en noviembre de 1938 que tenía 15 comentarios para el libreto intitulado "Juarez". Entre estos destacaba su tercer señalamiento que se refería al hecho de que "Juárez está luchando con una idea, y no con Maximiliano. / (Pasteur luchó contra los microbios - pero no los odiaba)". En el punto cuarto Muni también criticaba que "Tal y como aparece en el guion ahora, Uradi en relación con la cuestión racial parece ser un oponente único y solitario, y por esto, se convierte en un 'villano’ en la película”. Así es que después de incorporar los cambios sugeridos por Muni,33 se pasó a la etapa de preproducción donde Anton Grot, director del departamento de arte, crearía, a partir de grabados de época cerca de 3,500 bocetos con los cuales se prepararon más de 7,000 planos para los sets de filmación en los estudios de Warner. Ade-

32 Rodolfo Usigli rememora la visita de Wallis, Muni y Dieterle y de cómo pudo departir con ellos en una mesa reservada en el restaurante Rossignol, de Manolo del Valle. La plática abarcó, según Usigli, "ecos de Hollywood, títulos de cintas, nombres de actores, directores y empresas... entrecruzados con alusiones y referencias al Museo de Chapultepec, a la historia del Segundo Imperio y a las viejas culturas mexicanas, y con frecuentes libaciones de tequila de Wallis y Dieterle... Entre una cosa y otra pude cambiar breves frases con Muni, respondiendo a sus preguntas sobre Juárez, su obra y su tiempo, y haciéndole otras sobre su visión del tema y la interpretación que proyectaba para su personaje...” (Usigli, 2005: 555).

$33 \mathrm{Al}$ final los guionistas reunieron cerca de cuatrocientos libros sobre el tema de la invasión francesa en México. 
más, un pueblo mexicano fue construido en el rancho de Warner en San Fernando Valley.

El papel de Napoleón III iba a contar con tres escenas que sumaban más de diez minutos en la película. En la primera, el monarca aparecía reunido con su gabinete y se le avisaba que los "yanquis" habían derrotado a los confederados. Enseguida el monarca mostraba su disgusto debido a las consecuencias negativas que podía acarrearle para la permanencia de su ejército en México. Pero justo aquí su esposa Eugenia lo tranquilizaba sugiriendo que debería pensar en quién podía asumir el trono mexicano apoyado por un plebiscito que demostrara la voluntad del pueblo en aceptar un gobierno europeo. En la segunda aparición se observa al pequeño monarca escuchando a un par de músicos mientras posaba montado en lo alto de un caballo de madera para un pintor.34 Justo en esa escena aparece John Bigelow, embajador de los Estados Unidos en Francia, quien hablaría sobre la doctrina Monroe y criticaría la presencia francesa en México. En la última aparición, se ve cómo Napoleón es confrontado por Carlota quien, de visita en las Tullerías, le pedía que no abandonara a su marido, el emperador Maximilano, y que, por tanto, mantuviera a su ejército en México para poder enfrentar a Juárez. La locura se desata, entonces, en la reina a la que vemos huir de la sala real para salir a través de una puerta en donde su silueta desaparece en medio de una escenografía totalmente en negro en un estilo expresionista que supo imprimirle Dieterle.

34 Delante de un extenso lienzo se observa el boceto de Napoleón III montando un caballo. Estos trazos parecen hacer referencia, por la postura, la vestimenta y el gorro, a los óleos ecuestres pintados por Charles Edouard Boutibonne o Alfred Dedreux. Sin embargo, debido a un anacronismo, no puede ser ninguna de la obra de éstos porque sus cuadros fueron pintados, respectivamente, en 1856 y 1858 , fechas que no coinciden con la escena que corresponde al año de 1865 cuando Bigelow es el embajador estadounidense en Francia. 
Para la producción de Juarez Warner pasó de un presupuesto inicial de \$1,200,000 dólares a la suma de \$1,750,000 (Riva, 1996: 78-79).35 Un costo que puede ubicarse como intermedio comparado con los presupuestos de otras películas producidas en ese mismo ańo como los \$4,100,000 de Selznick International Pictures y Metro-Goldwyn-Mayer para Gone With the Wind (Balio, 1995: 180) o los \$546,200 de Walter Wanger Productions para The Stagecoach (Gallagher, 2009: 202).

Al mismo tiempo Warner Brothers supo saltar sagazmente las trabas de las censuras interna y externa en los Estados Unidos -entre otros el Código Hays y la presencia diplomática nazi- para poder realizar una película de propaganda aludiendo indirectamente a Hitler quien, ya para entonces, se preparaba a romper el pacto de no agresión con Polonia al acercar sus tropas a puestos fronterizos con aquella nación. Para ello, la imagen del tirano francés funcionó una vez más para Dieterle pero de forma más aguda: por eso la cuestión étnica se convirtió en un tema primordial en la cinta. A través de la invasión francesa que pretendió -apoyada por algunos mexicanos- coronar el poder genealógico de una estirpe europea sobre un país de indios y mestizos, se daba eco al antisemitismo que el nazismo buscaba imponer en ese momento. En una de las escenas de Juarez se observa al general mexicano Tomás Mejía que está a las órdenes del archiduque Maximiliano. En recompensa el emperador lo nombra comandante del Ejército Imperial Mexicano, pero dicho nombramiento era rechazado:

35 Para el rodaje de la película fueron necesarios 69 días (Roddick, 1983: 194). Para asegurar el éxito comercial de Juarez, no hay que olvidar que Warner compró los derechos de una película que tocaba el mismo tema: Maximilian and Charlotte de producción independiente y dirigida por Miguel Contreras Torres. De esta forma los Estudios pudieron retener el estreno de la cinta de Contreras hasta diciembre de 1939, es decir ocho meses después de que Dieterle hubiera estrenado Juarez en Nueva York (Black, 1999: 317). 
—Comandante Mejía: Es un gran honor, Majestad Imperial [...] No puedo aceptarlo siendo indio. Soy indigno.

-Maximiliano: ¿Qué tiene que ver su raza con su capacidad de mando, general Mejía?

-CM: Todo, Majestad Imperial.

-M: Puesto que desciende del noble tronco azteca, no hay duda de que la herencia de su sangre es la más antigua en esta habitación... Es nuestra voluntad que asuma el puesto para el cual ha sido ascendido, y confiamos le hará gran honor.

Contra esta imagen del militar, de origen indio, que se somete a las órdenes de la corona europea, se levanta la de Juárez que se enorgullece y defiende a los mexicanos (Foto 5). El mensaje de la película era directo, como el propio Muni apuntaba:

el paralelo entre el intento del s. XIX del eje París-Londres-Viena buscando convertir a México en un protectorado y un campo para la explotación y lo que está sucediendo hoy en el mundo es muy parecido para que pueda ser ignorado.36

Muni, pues, estuvo consciente del símil que encerraba la narrativa de Juárez y a través de su encarnación como el presidente de México habló, en uno de sus parlamentos, de cómo el poder debía residir en el pueblo:37 "Usted ve, Porfirio, cuando un monarca desgobierna cambia a la gente, pero cuando un presidente desgobierna, la gente es quien lo cambia”.

36 New York Herald Tribune (22/04/1939), New York Public Library, Paul Muni Papers Series III, Box 6, T-Mss 1967-005.

37 En su película The Great Dictator, Chaplin utilizaría el mismo procedimiento retórico como se observa en el discurso final que lleva a cabo el barbero que se hacía pasar por Hynkel (o Hitler), dictador de Tomania. 


\section{Emile Zola}

Otra imagen retórica próxima al símil es la del desplazamiento en el cual el adjetivo recae, dentro de la frase, no sobre el sustantivo natural sino en otro elemento más. Bajo esta óptica, en la película The Life of Emile Zola (1937), el traslado provenía de la actuación de Muni que ejecutaba el papel del novelista francés y no el de Dreyfus que sería el "natural" por tratarse de aquel oficial francés de origen judío acusado de espionaje.38 Desde luego, este razonamiento perdería sentido, en primer término, si no se considera que era un biopic cuyo centro es Zola y no el militar denostado. Pero, en segundo término, está el hecho de que Muni también era la estrella del momento por lo cual su llamado a interpretar el papel protagónico resultaba lo razonable. De hecho Muni, en la vida real, iba a tener un papel importante como patriota solidario para denunciar, desde los Estados Unidos, los atropellos al que estaban siendo sujetos los judíos. En todo caso, en el campo del arte cinematográfico es natural el desplazamiento: para los buenos actores no existen fronteras, por ejemplo, de etnia o religión. Pero en ese momento de persecución antisemita, encarnar al autor francés Zola, le permitía a Muni no solamente tener el rol estelar sino incluso defender a sus hermanos de sangre.39 Este hecho no pasó

38 Para Bob Herzberg (2011: 45), Paul Muni fue un actor liberal que firmó contrato con un Estudio liberal. Además indica que aunque Muni fue un judío orgulloso, no gustaba de interpretar papeles como tal en la pantalla. Pero a fin de cuentas sí participó en obras donde se mostraba a los judíos de manera positiva como en el caso de la cinta Zola o en las obras de Broadway: Wewillnever die (1943), un tributo a los judíos europeos masacrados, o A flagisborn (1946) que hablaba del retorno de los judíos a Israel.

39 Sobre la película de Dieterle, un artículo de Arthur Boehnel va a destacar el propósito propagandístico de la película Zola: "[Los productores] presentan el caso Dreyfus con fuerza, valentía, terriblemente y, al mismo tiempo, establecen paralelos modernos... 'La vida de Emile Zola' arremete contra la hipocresía, la 
desapercibido para la revista Time que destacó a Paul Muni en una de sus portadas de 1937 (Foto 6).40

En cuanto al papel de Dreyfus, sería el actor austríaco de origen judío Joseph Schildkraut quien se haría cargo de encarnarlo en la película en las diferentes etapas del caso:41 desde su acusación, su desafuero militar y su liberación final, pasando por sus ańos de reclusión en la Isla del Diablo. No es casual que las escenas que recrean el momento del maltrato y aislamiento del oficial judío revelen lo que será una realidad en los futuros campos de concentración nazi.

burocracia, la intolerancia, la estupidez de una manera sutil. Sólo el despreocupado dejará ver su paralelo con lo que está pasando en hoy en Alemania", Arthur Boehnel, "Three Fine Pictures Stirring Propaganda", en New York World (30/08/1937) New York Public Library, Paul Muni Papers Series III, Box 6, T-Mss 1967-005.

40 Time (16/08/37) New York Public Library, Paul Muni Papers Series III, Box 6, T-Mss 1967-005. Hay que tener presente que Paul Muni ya participaba en actividades propagandísticas a favor del pueblo judío. Por ejemplo, en septiembre de 1937 Muni fue llevado al Jewish Hall of Fame como uno de los 120 más importantes judíos del mundo. La conformación del salón había sido votado por estudiantes judíos de Chicago. Unos días más tarde Muni fue nombrado miembro del Consejo de la Liga Anti-Nazi de Hollywood para la Defensa de la Democracia Americana (Druxman, 1974: 68). Por su parte, Dieterle también participó en campañas de concientización fuera de los escenarios. Por ejemplo, en 1941 publicó el artículo "Hollywood and the European Crisis" al lado de sociólogos expertos en estudios de la comunicación como Max Horkheimer, Paul Lazarsfeld, Harold D. Laswell y Theodor W. Adorno, Studies in Philosophyand Social Science (1941).

41 En el casting para el papel de Dreyfus fueron varios los actores que hicieron pruebas fotográficas vestidos con diferentes trajes. Entre ellos se conservan ocho fotos de Joseph Shildkraut: en tres aparece en uniforme (dos de frente y una de perfil); en cuatro aparece con barba y con ropas de prisionero, y en una más ya salido de la prisión. También se conservan tres fotos del actor americano Morris Carnovsky, de origen judío, quien terminaría por interpretar a Anatole France en la película. William Dieterle Box 1Coll. 17 exp. 4:1-17Exp. 4:6Zola. University of Southern California. 
Zola and His Time fue la biografía escrita por el historiador de origen judío Matthew Josephson en 1928, misma que sirvió de base para el guión elaborado por Norman ReillyRaine, Heinz Herald y GezaHerczeg; un trabajo que les hizo merecedores a un Oscar. En primer lugar, esteguiónfue enviado a ErnestLubitsch en la Paramount. Y aunque al realizador alemán le gustó,prefirió enviar el guión a su compatriota y amigo Henry Blanke, de Warner, justificando que él no tenía un actor como Muni. 42

Antes de morir Dieterle habló de Muni señalando que para ambos el cine había sido más que un mero entretenimiento. Desde luego les permitió tener un buen cartel y, por ende, sueldos. 43 Pero el profesionalismo fue la base para ambos. En el caso de Muni siempre estaba el empeño perfeccionista para lograr una buena actuación. 44

$42 \mathrm{Al}$ parecer Henry Blanke tuvo que defender la producción de la película ante los ataques del cónsul alemán, Georg Gyssling, haciéndole creer que el juicio a Dreyfus era sólo una parte pequeña de la película. David Denby, "Hitler in Hollywood", The New Yorker, (16/09/2013). / Casualmente el tema de Zola iba a convertirse para Muni en la segunda oportunidad para trabajar en una representación del caso Dreyfus. En 1924, él ya había producido la obra de Romain Rolland, Les loupes (1898), con Maurice Schwartz en el Yiddish Art Theatre. En la obra de tres actos, Muni también había actuado el papel del defensor Zola (Druxman, 1974: 165).

43 Para el rodaje de la película TheLife of Zola fueron necesarios 177 días (Roddick, 1983: 302). El presupuesto de la producción contó con un total de casi 700,000 dólares. De esta cifra, 32,000 fueron para el sueldo de Dieterle y 50,000 para el de Muni (Dumont, 1994: 94).

44 Sobre su actuación, Muni indicaba parte de su método: "A veces cambio la entonación de algunas palabras porque para mí han tomado un nuevo significado... escribo a menudo en los márgenes del guión las asociaciones de ideas y los sentimientos que se me ocurren mientras aprendo mis frases. Por ejemplo, en el discurso de Zola al jurado, escribí una página de notas que cambiaron totalmente mi entonación original. Cuando ensayé por vez primera este discurso, lo dije hablando fuerte y con énfasis. Luego empecé a reflexionar en el significado de estas palabras 'Franceses, os conozco, sé la vida que habéis llevado'. A medida 
Él es un actor sensible fácil de dirigir. Tú no tenías que decirle qué hacer; él ya lo sabía. En Zola, cuando hacíamos la escena de J'accuse, la repetíamos una y otra vez no porque yo no estuviera satisfecho, sino porque él no lo estaba. El set estaba caliente. Él llevaba un traje pesado y un maquillaje poco confortable. 45 La escena era larga -seis y medio minutos sin corte-46. Él no se quejaba. Él trabajaba hasta quedar exhausto. Los técnicos, los electricistas y el equipo de fotografía aplaudieron cuando la escena terminó sin defecto. 47

Pero al día siguiente Muni regreso al set para repetirla (Lawrence, 1974: 233-234) y volver a dar el famoso discurso:

—Émile Zola: En este momento solemne, en presencia de este tribunal, que es el representante de la justicia humana, ante Francia, ante el mundo entero, juro que ¡Dreyfus es inocente! Por todo lo que he ganado, por todo lo que he escrito a difundir el espíritu de Francia, les juro que es inocente. Que todo se derrita; mi nombre puede perecer si Dreyfus no es inocente. Él es inocente.48

que el discurso se volvía más vivo para mí, más fuerte, empecé a sentir que debía decirlo con más calma pero intensamente. Las asociaciones de ideas me ayudaron así a determinar la cadencia de mis réplicas" (Dumont, 1994: 92).

45 Perc Westmore, maquillista inglés, fue el encargado de transformar el aspecto de Muni en la representación de Zola a la edad de treinta, cuarenta y sesenta años de edad (Dumont, 1994: 92).

46 En realidad el plano secuencia con Paul Muni a cuadro profiriendo su discurso de defensa es solamente de dos minutos y medio. En cuanto a la escena del juicio, desde la defensa y el veredicto final con un pequeño intercorte a la prisión de Dreyfus y el primer plano al diario Le Figaro llamando a la liberación del militar, tiene una duración de cerca de cuatro minutos.

47 De hecho su monólogo en la película terminaba con el aplauso de una parte de las personas en el juzgado.

$48 \mathrm{El}$ parlamento original en inglés dice: "At this moment, in the presence of this tribunal, which is the representative of human justice, before France, before the whole world, I swear that Dreyfus is innocent! By all that I have won, by all that I have written to spread the spirit of France, I swear that he is innocent. 
Para William Dieterle, The Life of Emile Zola se convirtió en su biopic favorito, 49 ello no debido a que se tratara de la reconstrucción histórica detallada en tiempo y espacio, sino porque era una historia atractiva con un personaje cargado como él hacia la izquierda. Sin embargo, Dieterle reconocía y daba crédito a la cuidadosa producción de Warner para cada detalle como fotografía, escenografía o vestido. Un ejemplo es la reconstrucción pormenorizada de la sala del juzgado en donde, a partir de la recopilación de material de la época, los escenógrafos y los modistas habían podido reproducir en el set el momento del juicio no sólo en su arquitectura y mobiliario, sino incluso colocando a cada persona en su lugar perfectamente ataviada (Fotos 7 y 8 ).

Por estos detalles es que Dieterle no se arrepentía de haber llegado a los Estados Unidos. Ciertamente su salida de Alemania había sido causada por Hitler, pero después de todo desde ahí iba a poder combatir al führer gracias a

la organización, la técnica y la moral de estudio (que no se tiene hoy en día en cualquier lugar). La gente siempre estaba allí a tiempo y se podría empezar a tomar a las nueve en punto. Ellos estaban entusiasmados, y cuando se comenzaba una película uno se quedaba ahí hasta el final (Denby, 2013: 25).

May all that melt away; may my name perish if Dreyfus be not innocent. $\mathrm{He}$ isinnocent".

49 Ello a pesar de los problemas de censura que tuvo a través del Código Hays. Por ejemplo, Dieterle recordaba como "Nosotros sólo podíamos usar la palabra 'judío' tres veces (y recuerdo que un par de ellos fue editado)" (Flinn, 1975: 25). Según David Denby (2013: s.p.), la mención de la palabra "judío" fue completamente suprimida del filme, salvo cuando en un recuadro aparecía la clasificación "Religion: Jew" en lo que era un expediente militar. 


\section{A manera de conclusión}

Como se ha podido comprobar, los tres biopics de la mancuerna Dieterle-Muni buscaron servir de propaganda contra el régimen nazi. No se sabe cuáles hayan sido sus efectos en los diferentes públicos. Lo que es seguro es que mientras en los Estados Unidos, una película como la de Zola tuvo éxito comercial, en Alemania, Italia o Japón la película estuvo prohibida. 50 Eran tiempos de regímenes totalitarios cuyos líderes estaban interesados en controlar la circulación de conocimiento de hechos del pasado vinculados a problemas de antisemitismo en periódicos, libros o películas.

Dieterle y Muni estuvieron más que interesados en concientizar, al menos a los espectadores que vieran sus películas, para defender a los millares de Dreyfus que en ese momento estaban sufriendo la persecución. Así, gracias a la producción cinematográfica se participaba como un Zola colectivo en defensa de sus hermanos de sangre (Giovacchini, 2001: 86). Hay que enfatizar que este Zola cinematográfico, sin olvidar al Juárez y al Pasteur, fueron productos, en buena parte, de la inmigración europea de izquierda que supo producir películas en Hollywood.51 Así, para lograr su estrategia, Dieterle y Muni se dieron a la tarea de burlar la censura administrativa y comercial al interior y exterior de los Estados Unidos mediante imágenes metafóricas que aludían a un hombre sin alma como el führer.

50 Fue solamente hasta que terminó la Segunda Guerra Mundial que la película fue exhibida en estos países.

51 Hay que recordar que en el caso de Paul Muni, su llegada a los Estados Unidos fue anterior a esta oleada migratoria europea. Así que si Muni mantuvo una lucha antifascista fue más por una cuestión étnica que por una razón política de izquierdas como sí lo fue en el caso de Dieterle. De cualquier forma, aquella primera ola migratoria de los ańos de 1930 y 1931, procedente de Alemania y Austria, vio consagrado su trabajo a partir de 1937 con varios premios como los que recibieron algunos de los colaboradores de Dieterle (Kafka, 2003: 185-186). 
$\mathrm{Al}$ respecto, conviene imaginar el hecho, muy probable, de que Dieterle y Muni, al igual que Kracauer y Hitler, hayan contemplado una película expresionista como Homunculus (1916) de Otto Rippert. Una cinta que predijo "sorprendentemente a Hitler", pues su protagonista, un obsesionado y resentido Homunculus, se convertía en dictador de un gran país, y comenzaba a tomarse inaudita venganza por sus sufrimientos (Kracauer, 1985: 37-38). $\mathrm{Y}$ es que ciertamente la reacción ante las imágenes cinematográficas siempre difiere en cada receptor: unos pueden desear transformarse en un Homunculus, otros en sus férreos críticos tal y como fueron Dieterle y Muni. Ellos apostaron contrarrestar a este monstruo cinematográfico mediante la trilogía de biopics que aquí hemos revisado. A fin de cuentas se trató de una lucha contra el poder totalitario justo en un momento cuando decir Napoleón III significaba decir Hitler.

\section{Bibliografía}

Adorno, Theodor W., 1941, Studies in Philosophyand Social Science, núm. 1, New York, Institute of Social Research.

Balio, Tino, 1995, Grand Design: Hollywood as a Modern Business Enterprise, 1930-1939, Los Angeles, University of California Press.

Black, Gregory D., 2012, Hollywood censurado, Madrid, España, Akal.

Boehnel, A., 1937, "Three Fine Pictures Stirring Propaganda”, en New York World, s. d.

Burleigh, Michael, 2007, El Tercer Reich. Una nueva historia, México, Punto de Lectura.

Chandler, Charlotte, 2006, The Girl Who Walked Home Alone: Bette Davis, A Personal Biography, New York, Simon \& Schuster. 
Chaplin, Charles, 1993, Mi autobiografia, Madrid, España, Debate.

Debré, Patrice, 1998, Louis Pasteur, Baltimore, The John Hopkins University Press..

Conroy, Tiffaany Ann, 2012, Kosintsev's Shakespeare films: Russian Political Protest in Hamlet and King Lear, North Caroline, McFarland \& Co.

Denby, David, 2013, "Hitler in Hollywood. Did the studios collaborate?", en The New Yorker, s. p., disponible en: http://www. newyorker.com/magazine/2013/09/16/hitler-in-hollywood (consulado 16/IX/2013).

Doherty, Thomas, 2007, Hollywood's censor: Joseph I, Breen \& the Production Code Administration, New York, Columbia University Press.

, 2013, Hollywood and Hitler, 1933-1939, New York, Columbia University Press.

Dumont, Herve, 1994, William Dieterle. Antifacismo y compromiso romántico, Madrid-San Sebastián, Festival Internacional de Cine de San Sebastián.

Druxman, Michael, 1974, Paul Muni. His Life and His Films, New York, A. S. Barnes.

Eisner, Lotte H., 1998, La pantalla demoniaca, Madrid, Cátedra.

Elefteriou-Perrin,Veronique, 2004, "The motion picture is potentially one of the greatest weapons for the safeguarding of democracy: activismeet censure dans le monde hollywoodien des années 1930", Revue française d'études américaines, núm. 102, pp. 62-81.

Falkoswska, Janina, 2007, Andrezj Wajda: History, Politics, and Nostalgia in Polish Cinema, New York, Berghahn Books.

Elsaesser, Thomas, 1986, "Film history as social history: Warner Bros and the biopic", Wide Angle, núm. 8, pp. 15-31. 
Flinn, T., 1975, "William Dieterle, The Plutarch of Hollywood", The Velvet Light Trap, núm. 15, pp. 23-28.

Gallagher, Tag, 2009, John Ford, Madrid, España, Akal.

Giovacchini, Saverio, 2001, Hollywood Modernism: Film and Politics in the Age of the New Deal, Philadelphia, Temple University Press.

Grobel, Lawrence, 2000, The Hustons: The Life and Times of a Hollywood Dynasty, New York, Cooper Square Press.

Herzberg, Bob, 2011, The Left Side of the Screen: Communist and Left-Wing Ideology in Hollywood, 1929-2009, North Carolina, Mcfarland and Company.

Hobsbawm, Eric, 1998, La era del capital, 1848-1875, Buenos Aires, Crítica.

Humphries, Reynold, 2009, Las listas negras de Hollywood: Una historia cultural y política, Barcelona, Península.

Kafka, Hans, 2003, "What Our Immigration Did for Hollywood, and Viceversa”, New German Critique, núm. 89, pp. 185-189.

Kracauer, Siegfried, 1960, Theory of Film. The Redemption or Physical Reality, New York, Oxford University Press.

, 1985, De Caligari a Hitler: una historia psicológica del cine alemán, Barcelona, Paidós.

Latour, Bruno, 1995, Pasteur, una ciencia, un estilo, un siglo, México, Siglo XXI.

Lawrence, Jerome, 1974, Actor. The Life and Time of Paul Muni, New York, G. P. Putnum's.

Mazierska, Ewa y Goddard, Michael (eds.), 2014, Polish Cinema in a Transnational Context, New York, University of Rochester Press. 
Medina, Pedro, Luis Mariano González y José Martín Velázquez, 1996, Historia del cortometraje español, Alcalá de Henares, España, Festival de Cine de Alcalá de Henares.

Mitchell, W. J. T., 2009, Teoría de la imagen, Madrid, Akal.

Mitry, Jean, 1990, La semiología en tela de juicio (cine y lenguaje), Madrid, Akal.

Pasteur, Valery-Radot, 1933, "La théorie des germes et ses applications á la médecine et à la chirurgie", Oeuvres de Pasteur, Francia, Masson et cie., núm. 6, pp. 112-130.

Paz, María Antonia y Julio Montero, 2002, El cine informativo 1895-1945. Creando la realidad, Barcelona, Ariel.

Pitol, Sergio, 1995, "El gran teatro del mundo", Revista Universidad de México, núm. 533.

Robé, Chris, 2009, “Taking Hollywood Back: The Historical Costume Drama, the Biopic, and Popular Front U.S. Film Criticism”, Cinema Journal, núm. 48 (2), pp. 70-87.

Riva, Osa Hidalgo de la, 1996, "A Chicana Rereading of Juarez", Spectator, núm. 17 (1).

Roddick, Nick, 1983, A New Deal in Entertainment. Warner Brothers in the 1930s, London, Garden House Press.

Ross, Stewart Halsey, 2006, How Rooselvet failed America in World War II, North Carolina, MacFarland \& Company.

Sadoul, Georges, 1972, Historia del cine mundial. Desde los orígenes hasta nuestros dias, México, Siglo XXI.

Urwand, Ben, 2013, The Collaboration: Hollywood's Pact With Hitler, Cambridge, Massachusetts, The Belknap Press of Harvard University Press.

Usigli, Rodolfo, 2005, Teatro completo: Escritos sobre la historia del teatro en México, México, FCE. 
Zalampas, Sherre Owens, 1990, Adolf Hitler : a Psychological Interpretation of his Views on Architecture, Art, and Music, Bowling Green University Popular Press.

\section{Archivos}

Doheny Library, Special Collections, William Dieterle, University of Southern California.

New York Public Library, Paul Muni Papers.

Recibido: 20 de abril de 2016 Aceptado: 2 de septiembre de 2016 


\section{Anexos}

Fotos 2 y 3. Fotogramas de la película Pasteur
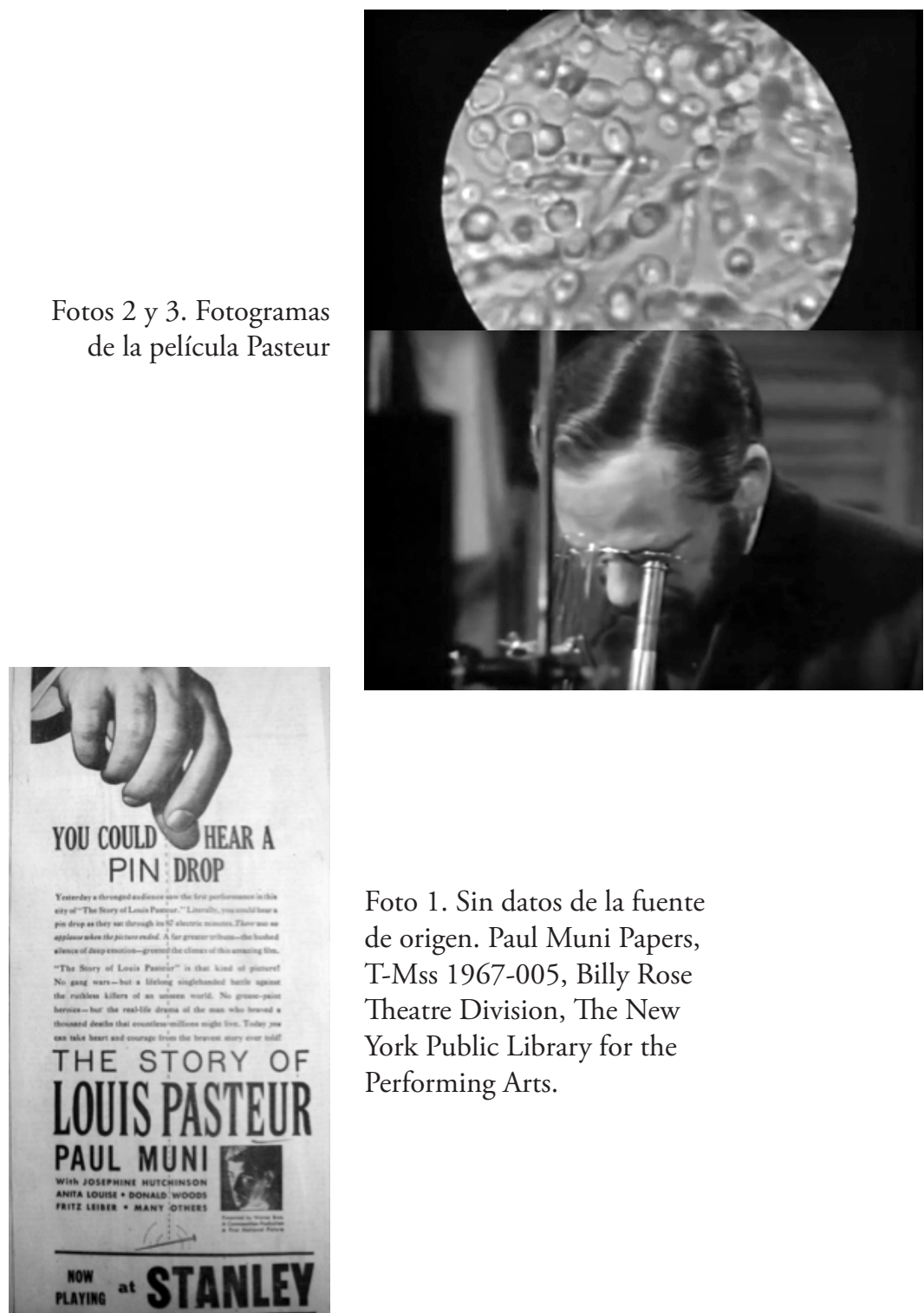

Foto 1. Sin datos de la fuente de origen. Paul Muni Papers, T-Mss 1967-005, Billy Rose Theatre Division, The New York Public Library for the Performing Arts. 
Foto 4. Sin datos de la fuente de origen. Paul Muni Papers, T-Mss

1967-005, Billy Rose

Theatre Division, The New York Public Library for the Performing Arts

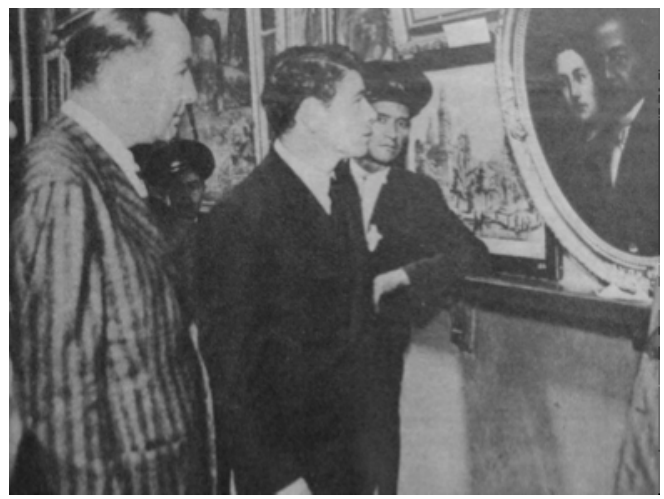

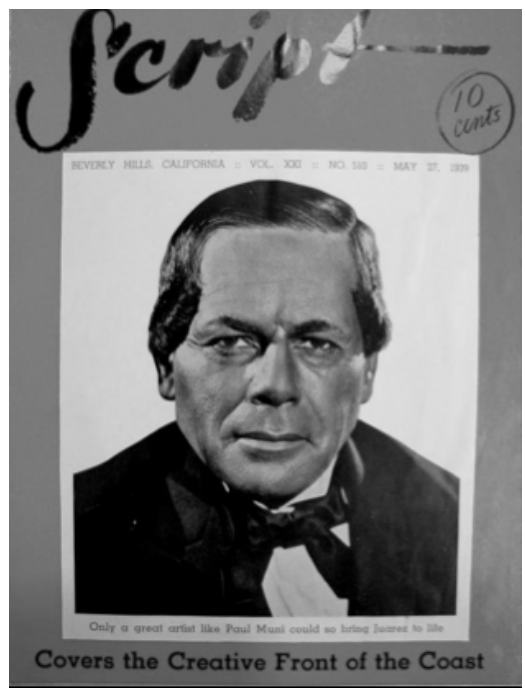

Foto 6. Time. The Weekly News Magazine, vol. XXX, no. 7, 16/08/1937. Paul Muni Papers, TMss 1967-005, Billy Rose Theatre

Division, The New York Public Library for the Performing Arts.
Foto 5. Script, vol. XXI, no. 510, 27/05/1939. Paul Muni Papers, T-Mss 1967-005, Billy Rose Theatre Division, The New York Public Library for the Performing Arts.

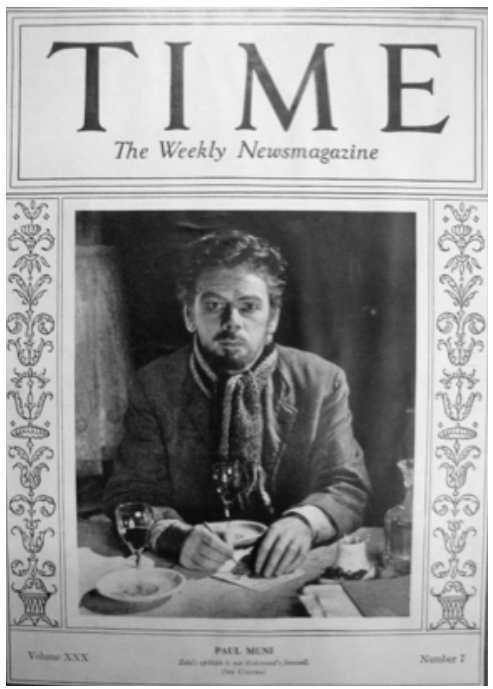




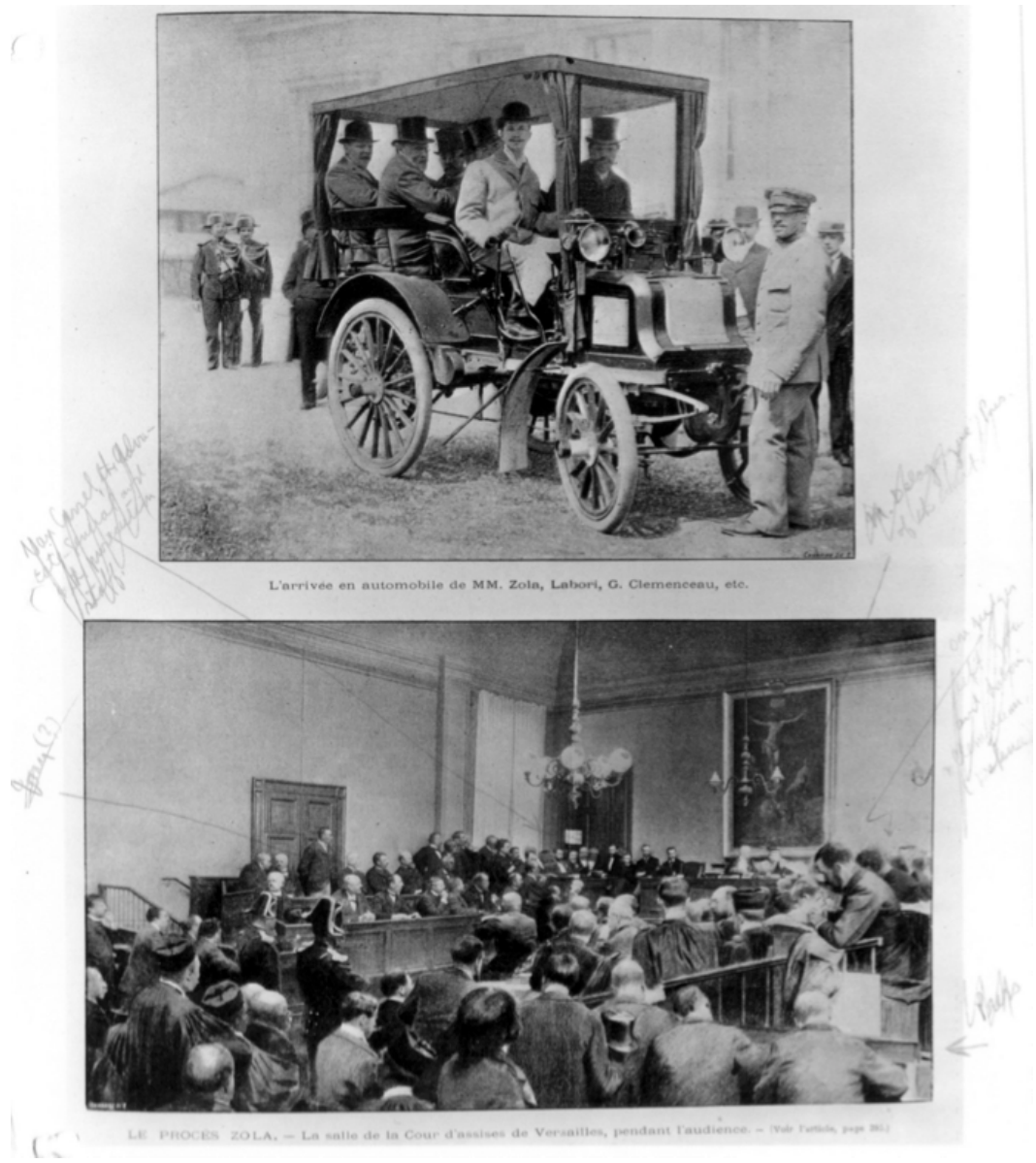

Fotos 7 y 8 . Foto superior: Zola en el coche que lo llevaría a la sala de Corte. Foto inferior: Reproducción de sala de audiencias (Versalles) con la presencia de Zola. Nótese las marcas manuscritas en esta hoja con las dos fotos que permiten ver la reconstrucción pormenorizada de las escenografías identificando a los personajes presentes en el juicio de Dreyfus. William Dieterle 64. Box 4: 10. Cortesía: University of Southern California. 